OSAS

\title{
Transoral glossoepiglottopexy in the treatment of adult obstructive sleep apnoea: a surgical approach
}

\section{Glossoepiglottoplastica con approccio trans-orale nel trattamento delle apnee ostruttive notturne nell'adulto}

\author{
V. ROUSTAN ${ }^{1}$, M. BARBIERI ${ }^{1}$, F. INCANDELA ${ }^{1}$, F. MISSALE ${ }^{1}$, H. CAMERA ${ }^{1}$, F. BRAIDO ${ }^{2}$, R. MORA ${ }^{1}$, G. PERETTI ${ }^{1}$ \\ ${ }^{1}$ Department of Otorhinolaryngology and Head and Neck Surgery, ${ }^{2}$ Allergy and Respiratory Diseased Clinic DIMI, \\ University of Genoa, IRCCS AUO San Martino-IST, Genoa, Italy
}

\begin{abstract}
SUMMARY
The treatment of obstructive sleep apnoea syndrome (OSAS) is still a matter of debate; among the different therapeutic alternatives, both surgical and conservative, treatment with continuous positive airway pressure (CPAP) is considered the "gold standard". The recent scientific literature reports that even if CPAP represents an effective solution for sleep apnoeas, $12 \%$ of patients do not benefit from its use. In most cases, primary collapse of the epiglottis is responsible for failure. We developed a surgical technique that provides a stable support to the epiglottis without influencing its function during swallowing while preserving laryngeal anatomy and physiology. The procedure we propose is based on that conceived by Monnier for children affected by laryngomalacia. We analysed a group of 20 patients who underwent glossoepiglottopexy between January 2015 and September 2016 and compared data (AHI, ODI, t90, ESS, EAT10, etc.) collected before and 6 months after surgery to demonstrate the safety and effectiveness of our glossoepiglottopexy (GEP). The results allow us to consider GEP as a valid choice to treat adults who suffer from sleep apnoeas.
\end{abstract}

KEY WORDS: OSAS • Epiglottis • Transoral laser microsurgery (TLM)

\section{RIASSUNTO}

I dati della letteratura scientifica internazionale stabiliscono che almeno il 10\% della popolazione adulta sia affetto da Sindrome delle Apnee Ostruttive nel Sonno (OSAS). Nonostante le numerose proposte terapeutiche, chirurgiche e non, che si sono susseguite negli anni, la ventiloterapia con C-PAP rappresenta ad oggi il gold standard per il trattamento di questi pazienti. Esiste comunque una percentuale di pazienti, stimata attorno al $12 \%$, che non trae beneficio dalla terapia ventilatoria o che, addirittura, peggiora in corso di C-PAP; il collasso primario dell'epiglottide, ovvero quello dipendente esclusivamente da un'eccessiva lassità della cartilagine, verso l'aditus laringeo rappresenta la causa più frequente di insuccesso in questi soggetti. Sulla base di queste osservazioni abbiamo deciso di sviluppare una tecnica chirugica volta unicamente alla stabilizzazione dell'epiglottide che fosse conservativa e potenzialmente reversibile. La procedura che proponiamo prende spunto dall'epiglottoplastica proposta da Monnier per i pazienti pediatrici affetti da laringomalacia. Lo studio comprende 20 pazienti sottoposti a glossoepiglottoplastica tra Gennaio 2015 e Settembre 2016; diversi parametri (tra i quali AHI, ODI, t90, ESS, EAT10 ed altri) sono stati confrontati tra quelli registrati nel per operatorio e dopo 6 mesi di follow-up per valutare l'efficacia dell'intervento chirurgico. I risultati evidenziano come la glossoepiglottopessi rappresenti una valida possibilità di trattamento delle epiglottidi primarie responsabili della sindrome delle apnee ostruttive notturne nell'adulto.

PAROLE CHIAVE: OSAS • Epiglottide • Microchirurgia laser transorale (TLM)

Acta Otorhinolaryngol Ital 2018;38:38-44

\section{Introduction}

Obstructive sleep apnoea (OSA) is a disorder caused by repetitive collapse of the upper airway during sleep, resulting in either partial or complete airflow obstruction ${ }^{12}$. In the adult population, the prevalence of OSA is $22 \%$ in men and $17 \%$ in women ${ }^{3}$. The morphology of upper- airway structures plays a major role in the pathogenesis of OSA.

Treatment of OSA with continuous positive airway pressure (CPAP) is currently considered as the "gold standard". Despite its proven efficacy, a significant number of patients cannot tolerate the device and require therapeutic 
alternatives such as surgery, oral appliances and/or positional devices.

In the past, the prevalence of epiglottis collapse evaluated by clinical examination was estimated to be $12 \%$ in OSAS patients, although nowadays thanks to the introduction of drug-induced sedation endoscopy (DISE) it is possible to show that the prevalence of epiglottis collapse in determining the airway obstruction is actually much higher ${ }^{4-6}$, and also allows for stratification of OSAS into different levels of obstruction. Nonetheless, the role of the epiglottis in airway collapse still remains a matter of debate in the medical community ${ }^{17}$.

The laxity of the epiglottis is widely discussed in the paediatric literature as one of the possible presentations of congenital laryngomalacia; however, laryngomalacia in adults is a rare entity that has not been clearly described. Primary collapse of the epiglottis represents a challenging situation because CPAP treatment may aggravate airway obstruction by further pushing the epiglottis down into the laryngeal aditus ${ }^{8}$, and up to now no standardised surgical procedures have been described.

Herein we describe a new surgical procedure, obtained by modifying Monnier's glossoepiglottopexy, used in malacic epiglottis in children ${ }^{9}$, with the aim to resolve the collapse of the epiglottis in adults without interfering with its fundamental functions.

\section{Materials and methods}

From January 2015 to September 2016, 20 patients (16 males and 4 females), aged between 35 and 65 years old (mean 49.2) affected by OSAS underwent glossoepiglottopexy at the Department of Otorhinolaryngology and Head and Neck Surgery of the University of Genoa. All patients were submitted to multilevel surgery (nasalpharyngopalatal-laryngeal) performed by a senior surgeon. If tonsils were still in place a tonsillectomy was performed ${ }^{10}$, sparing the palatoglossus and palatopharyngeus muscles and as much as possible the mucosal covering both pillars ${ }^{11}$. Septoplasty and turbinoplasty ${ }^{12}$ was performed if needed ${ }^{13}$

All patients were evaluated in a preoperative setting and after 6 months after surgery by clinical, polysomnographic and endoscopic assessment. All data were extracted from a single database ${ }^{14}$.

Inclusion criteria were: OSA confirmed by sleep study (with an apnoea hypopnoea index (AHI) $\geq 15$ episodes/h, BMI $<35 \mathrm{~kg} / \mathrm{m}^{2}$; primary epiglottic collapse evaluated by drug-induced sedation endoscopy (DISE) and Laryngoscore $<6^{15}$.

Major comorbidities, severe tongue base hypertrophy, secondary epiglottis, cranio-facial malformations and laryngeal dysfunction were considered exclusion criteria. The study was approved by our institutional review board.

\section{Clinical evaluation}

Clinical evaluation included a complete head and neck examination as well as body mass index (BMI) calculation. Moreover, all patients were evaluated by a comprehensive history that covered sleep habits and sleep disturbances. Excessive daytime sleepiness was estimated by the Epworth sleepiness scale (ESS) ${ }^{16}$, while swallowing by the Eating Assessment Tool (EAT 10) ${ }^{17}$ and the penetration aspiration scale ${ }^{18}$. EAT 10 is a self-administered, symptom-specific outcome survey that was investigated before and one week after surgery, while the penetration aspiration scale is an endoscopic finding that expresses the accidental loss of food or liquid into the airway while eating or drinking.

The possibility to have an adequate exposure of the larynx by a trans-oral approach was evaluated by the Laryngoscore ${ }^{15}$.

\section{Polysomnographic study}

Polysomnographic study was performed with a cardiorespiratory monitor (Vital night, Vital aire, Milan Italy) to record the following variables simultaneously: nocturnal snoring sound, arterial oxygen saturation measured by finger oximetry, body position, nasal and mouth airflow, thoracic and abdominal respiratory movements recorded by inductive plethysmography and heart rate. The entity of sleep apnoea was evaluated by: AHI; oxygen desaturation index (ODI); $\mathrm{T}<90 \%$ (average desaturation and the percentage of total time with oxygen saturation level lower than 90\%); mean oxygen saturation ( $\mathrm{SpO} 2$ mean).

\section{Endoscopic evaluation}

Flexible video nasopharyngoscopy (V-NFL) was used for endoscopic evaluation. To perform this procedure, we used a transnasal flexible endoscopy using an ENF-V2 videoendoscope connected to an EvisExera II CLV-180B light source (Visera Elite OTV-S190, Olympus Medical Systems Corporation, Tokyo, Japan), integrated with highdefinition television (HDTV). Upper airway and digestive tract morphology was examined. The Muller manoeuvre was performed in a sitting position to determine the extent of retropalatal (Muller RP) and retrolingual (Muller RL) obstruction; it was considered significant when the percentage of collapse of the airway was at least $50 \%$.

\section{Drug-induced sedation endoscopy (DISE)}

DISE was performed in a supine position without neck extension. The entire exam was recorded. No local anaesthesia was used in the nasal cavity according to the Eu- 
ropean position statement on DISE ${ }^{19}$. Sleep was induced with a bolus of $1.3 \mathrm{mg}$ of midazolam in pre-anaesthesia and intravenous propofol in target controlled infusion (TCI) $\left(1.1-1.6 \mu \mathrm{g} / \mathrm{ml}\right.$ according Schnider's model) ${ }^{20}$. The degree of obstruction was evaluated at the level of the nasal cavity, nasopharynx, oropharynx, hypopharynx and larynx using the NOHL classification ${ }^{21}$.

\section{Surgical technique}

During microlaryngoscopy, the patient lies supine in Boyce-Jackson's position with the eyes protected by wet bandages and the superior teeth by a silicone device. The smallest efficient tube (Laser Shield ${ }^{\circledR}$ II Endotracheal Tube, Medtronic Xomed, Jacksonville, FL USA) for trans oral-intubation was chosen. Exposure of the supraglottis and the base of the tongue was obtained by a Sataloff laryngoscope (Microfrance Sataloff Laryngoscopes 124, Medtronic ENT, Jacksonville FL USA) to achieve adequate exposure of both the base of the tongue and the entire valleculae and epiglottis. The position of the hyoid bone was marked on the skin as a landmark.

A CO2 laser (Ultrapulse Dualpro Laser CO2, Lumenis, Yokneam, Israel), set on ultrapulse mode, at 3 watts of delivered power at a $400 \mathrm{~mm}$ working distance, was used to vaporize the mucosa overlying the valleculae and the base of the tongue and outlining two raw areas leaving a rim of 2-4 $\mathrm{mm}$ of healthy mucosa along the entire profile of the supra-hyoid epiglottis. The cicatricial retraction during the healing process determined an iatrogenic synechia attracting the epiglottis to the tongue base ${ }^{14}$. The surgical field was mostly bloodless thanks to the ability of the $\mathrm{CO} 2$ laser to coagulate vessels with a diameter less than $0.5 \mathrm{~mm}$. For larger vessels, cauterising monopolar forceps was routinely adopted and surgical clips are also strongly recommended. In case of hypertrophy of the lingual tonsils, resection of the lymphatic tissue may be combined. A cottonoid, soaked in saline solution, was applied intraoperatively to remove char and clean the raw surface for detection of any residual intact mucosal island as a cause of possible retention cysts when the two surfaces adhere to each other.

To ensure complete sealing of the pexy, two Premilene ${ }^{\circledR}$ sutures number 1 (Premilene, Braun, Melsungen Germany) embraced the hyoid bone guided by means of two 16 gauge catheters. The first suture was bent in the middle to form a loop and was inserted inside the first needle to exit from the tip. Later, the catheter was passed through the skin, in a supra-hyoid position, along the midline to avoid vascular injuries, until reaching the glosso-epiglottic vallecula. This procedure was monitored under microscopic control (Fig. 1). The needle was then pushed through the epiglottis and retrieved out of the mouth.
The second suture was inserted into the second catheter and penetrated soft tissues beneath the hyoid (Figs. 2, 3). Finally, the surgeon inserted the proximal end of the wire

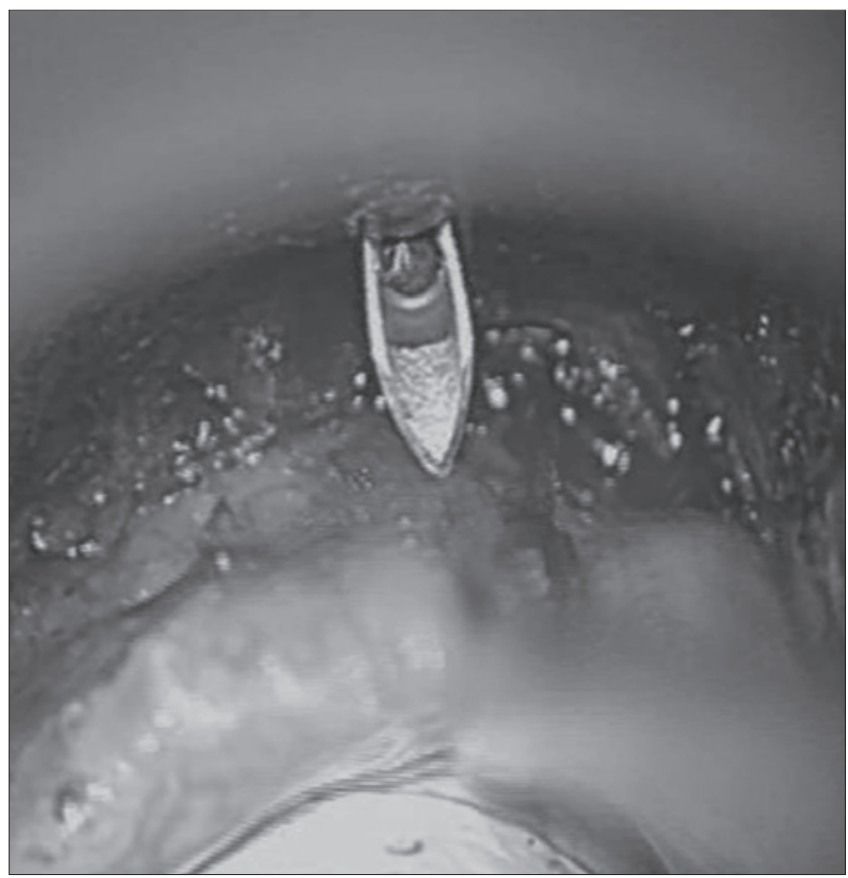

Fig. 1. The first needle penetrates the skin of the neck in a suprahyoid position. This needle contains a suture bent to form a loop. In MLSD the first surgeon controls that the needle penetrates the epiglottis in a correct position and he then retrieves the loop out of the mouth.

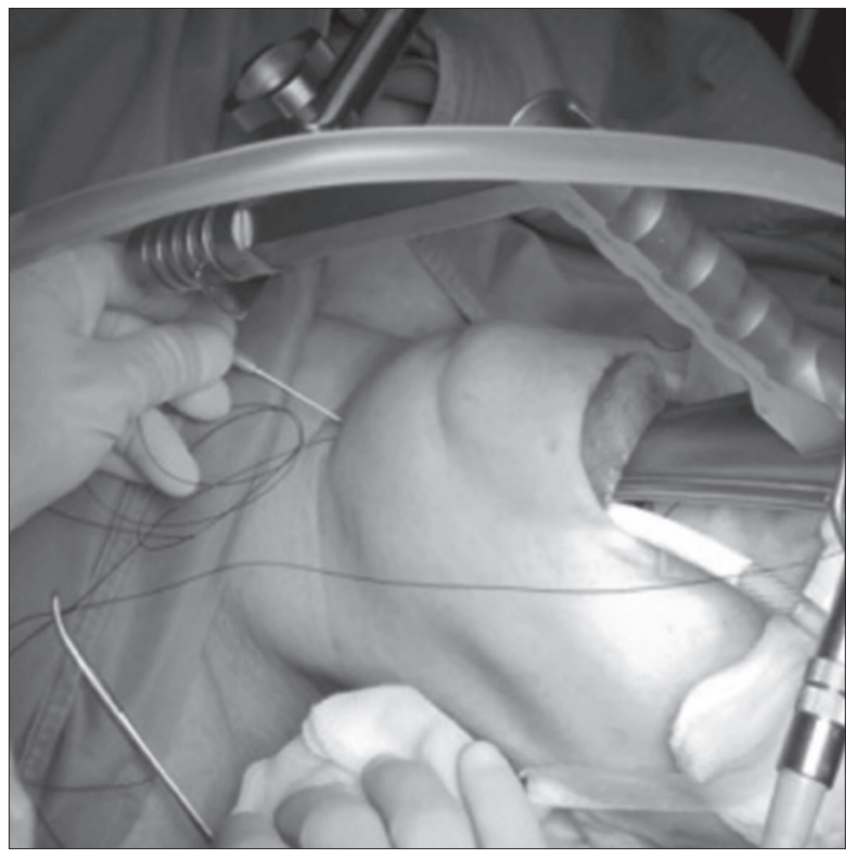

Fig. 2. The second suture was inserted into the second catheter and penetrated soft tissues beneath the hyoid. 


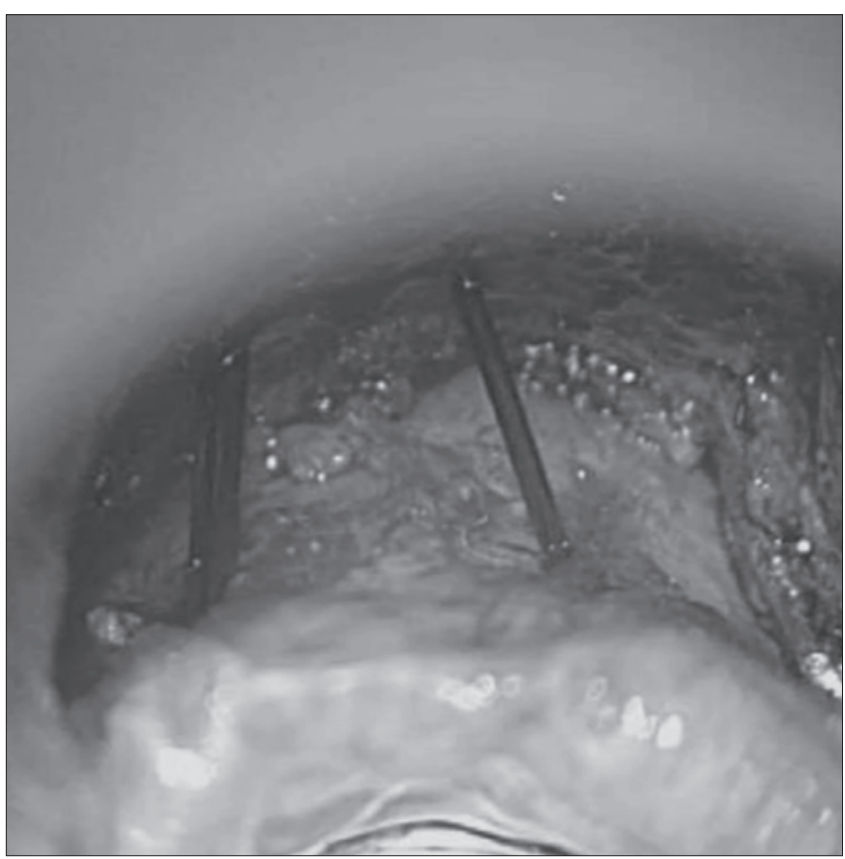

Fig. 3. Endoscopic view after the insertion of the second suture.

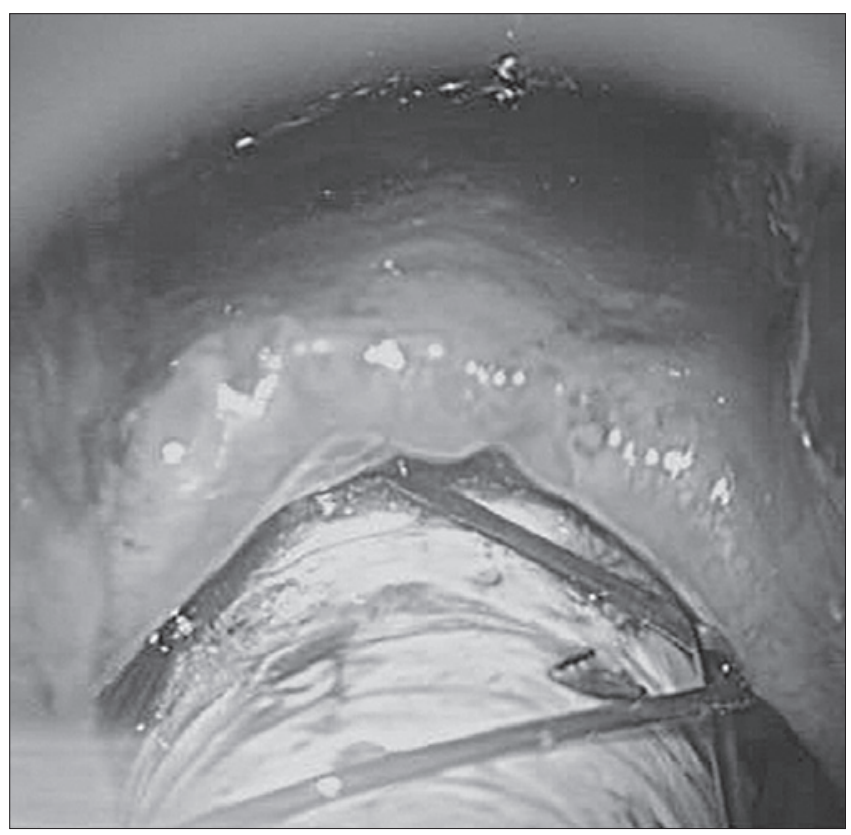

Fig. 4. The proximal end of the wire is inserted within the loop that is used as a guide to make the free suture exit the neck.

within the loop while holding it with one hand (Fig. 4). The second surgeon retracts the distal part of the loop, with a firm movement, allowing the second suture to exit from the skin. Both wires are then fixed anteriorly to the larynx using a Silastic sheet, on the anterior neck, to protect the skin from local trauma. Before tying the suture, a small amount of

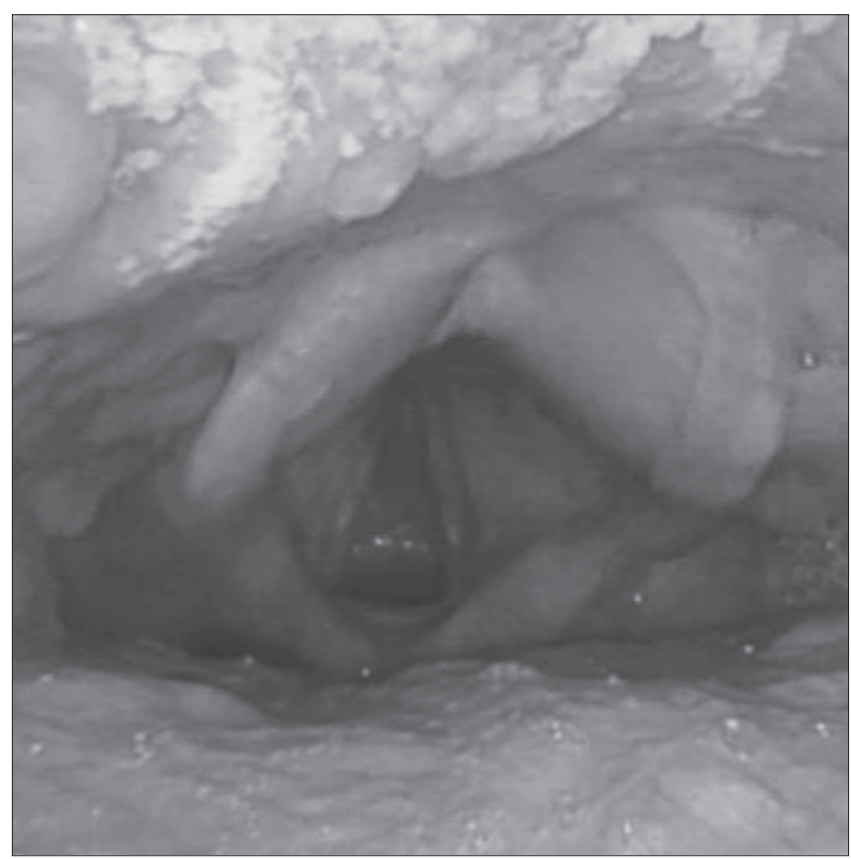

Fig. 5. The suture is removed after 4 weeks under endoscopic control. The epiglottis results perfectly stabilised.

Tissee ${ }^{\circledR}$ (Baxter, Westlake Village, CA USA) is spread in the glosso-epiglottic vallecula using a Duplocath ${ }^{\circledR}($ Baxter, Westlake Village, CA USA) catheter.

\section{Postoperative care}

The patient was extubated at the end of the procedure. A clinical swallow evaluation was obtained on the first postoperative day. In case of normal scores, the patient was allowed to resume oral intake, including thin liquids, and was placed on a soft diet for 1 week. Intravenous antibiotics were administered for 24 hours. The patient was discharged after 48 hours of observation. Oral antibiotics and analgesics were recommended for one week.

The stich was removed endoscopically after 4 weeks (Fig. 5); neither general or local anaesthesia is required.

Flexible laryngoscopy was performed after 1 week, testing the penetration-aspiration scale, and was repeated 3 weeks postoperatively. All patients filled in the EAT 10. All subjects also underwent an additional polysomnography testing 6 months after the procedure, while postoperative views were recorded at the time of control polysomnography.

\section{Statistical analysis}

Statistical analysis was performed with IBM SPSS Statistics version 24.0. Data were collected on a paired sample basis and comparisons were done using a nonparametric Wilcoxon Signed Rank Test. The Wilcoxon Signed Rank 
Test was used to test for statistically significant differences between pre- and post-operative parameters. $\mathrm{P}<0.05$ was accepted as statistically significant.

\section{Results}

Twenty patients affected by OSAS with primary epiglottic collapse were included in this study. All patients (100\%) underwent glossoepiglottopexy and pharyngoplasty, according to the palatal conformation: $10(50 \%)$ Barbed Reposition Pharyngoplasty (BRP) ${ }^{11}, 6$ (30\%) Functional Expansion Pharyngoplasty (FEP) ${ }^{22}, 4$ (20\%) Barbed Roman Blinds Technique (BRB) ${ }^{23} 24$. Tonsillectomy was performed in $11(55 \%)$ patients and septoplasty and turbinoplasty in $4(20 \%)$ patients (Table I).

Transoral glossoepiglottopexy was associated with a significant decrease in ESS scores $(p<0.001)$ evaluated at 6 months after surgery $(16.5 \pm 4.3$ vs. $3.1 \pm 2.5)$.

Clinical swallow evaluation and EAT-10 score was normal in all the patients; in particular, only one patient reported that extra effort was needed to swallow pills, with a total score of 2 . All patients received a score of 1 on the penetration-aspiration scale in their first swallows.

Mean \pm sd AHI values were $23.6 \pm 6.5$ and $5.2 \pm 3.2$ events/ hour, before and six months after surgery respectively, and this difference was statistically significant $(\mathrm{p}<0.001)$. ODI presented a significantly lower value at 6 months after surgery $(19.3 \pm 6.1$ vs. $4.8 \pm 2.7, \mathrm{p}<0.001)$. There was a significant decrease of $\mathrm{T}<90 \%$ values, which decreased from $9.7 \pm 3.4$ to $1.4 \pm 2.0(\mathrm{p}<0.001)$. Mean oxygen saturation (mean $\mathrm{SpO} 2$ ) showed an increase at final evaluation vs. pretreatment levels $86.9 \pm 2.3$ vs. $94.7 \pm 2.3(p<0.001)$ (Table I).

\section{Discussion}

A positive correlation between high BMI and OSA is well known in the literature; the pressure of the parapharyngeal fat pads and chronic collapse of the retroglottal airway during sleep create deformity of the epiglottis observed in patients with OSA. Thus, the shape of the epiglottis reflects the degree of the chronic airway obstruction. In patients suffering from OSAS, primary collapse of the epiglottis is due to the high negative intrathoracic pressure generated during obstructive events, in contrast to that which characterises laryngomalacia.

However, even when the epiglottis represents a cause of obstruction, its function in protecting the upper airway must be taken into account. The role played by the epiglottis in preventing inhalation of bolus is two-fold: on one hand, it offers a physical closure of the laryngeal aditus, while on the other its sensitive receptors (distributed on the laryngeal surface, ariepiglottic folds, arytenoids and posterior commissure)

Table I. Comparison of data collected before and 6 months after surgery.

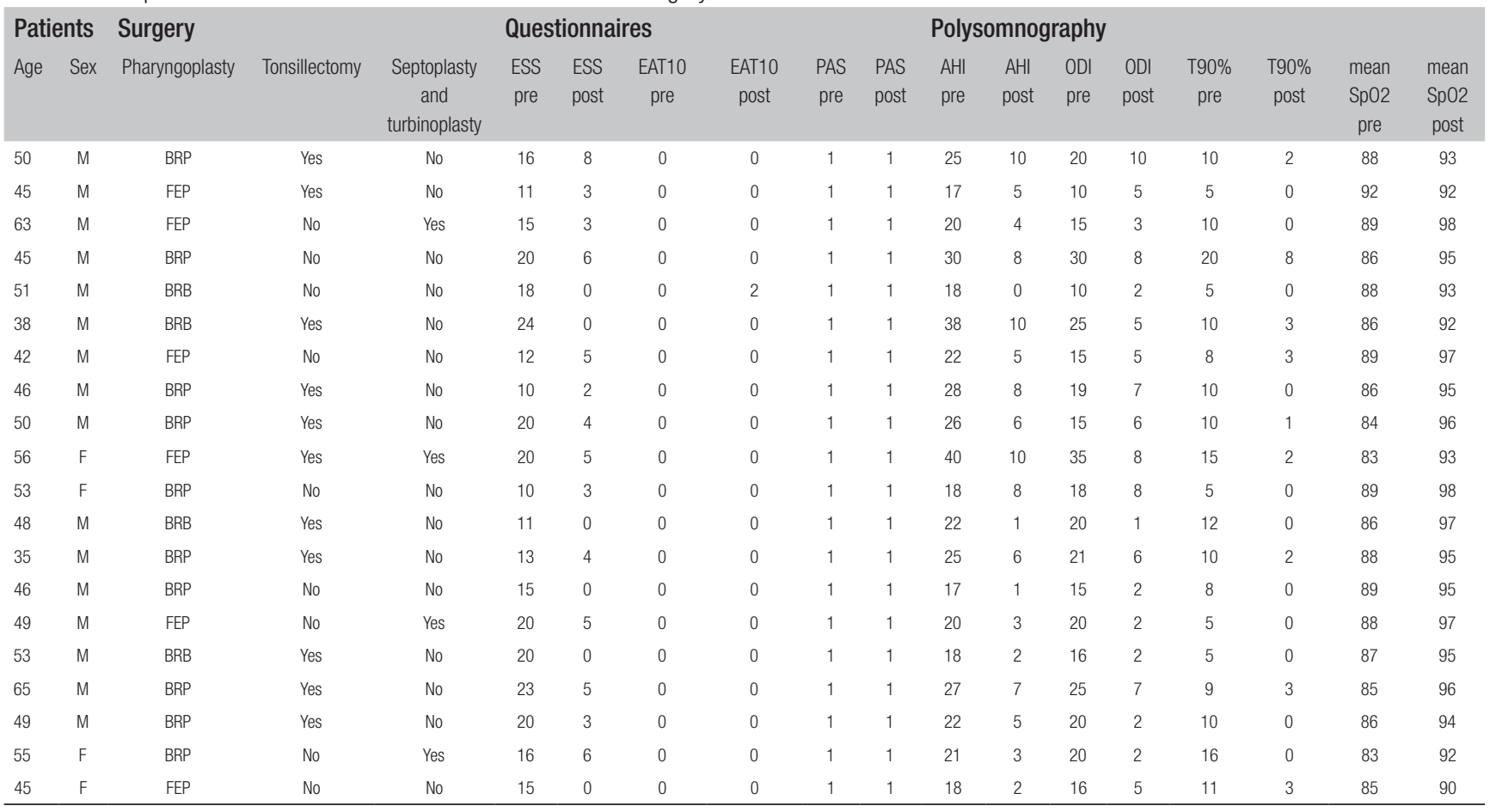


stimulate the so-called "glottis closure reflex". This reflex is coordinated by the vagal nerve, and more precisely by its superior laryngeal branch, which provides the abduction of the vocal folds during deglutition thus avoiding the entrance of bolus in the airways. To maintain these two functions, two technical precautions must be taken into consideration: 1 ) it is necessary to leave a $3-4 \mathrm{~mm}$ rim of healthy cartilage and mucosa along the entire profile of the epiglottis to address food to the piriform sinuses; 2) the mucosa of the supraglottis (except the lingual aspect of the epiglottis) and the glottis should be preserved to allow the activation of reflexes.

Since the advent of DISE, the indications for the laryngeal surgery for OSAS have significantly changed, due to the fact that the awake endoscopy with Muller manoeuvre alone underestimates the obstructive component at this level by $40 \%{ }^{25}$.

To date, surgical approaches in this region are technically complex, significantly invasive and associated with a high rate of complications, such as bleeding, oedema, persistent dysphagia, dysgeusia, etc. ${ }^{26}$. New technologies (diathermy, $\mathrm{CO} 2$ laser and co-blation) have allowed the introduction of innovative surgical techniques aimed at modifying the epiglottis and negatively interfering with its sphincter function ${ }^{27}$.

\section{Conclusions}

The surgical technique described herein is able to preserve laryngeal anatomy and physiology, and is safe and reversible in case of unexpected complications. Moreover, it provides stable support to the epiglottis without interfering with its function during swallowing and reinforces the wall of the airway by creating a type of landslide barrier for posterior falling of the tongue base.

\section{References}

1 Torre C, Camacho M, Liu SY, et al. Epiglottis collapse in adult obstructive sleep apnea: a systematic review. Laryngoscope 2016;126:515-23.

2 Ma MA, Kumar R, Macey PM, el al. Epiglottis cross-sectional area and oropharyngeal airway length in male and female obstructive sleep apnea patients. Nat Sci Sleep 2016;8:297-304.

3 Franklin KA, Lindberg E. Obstructive sleep apnea is a common disorder in the population-a review on the epidemiology of sleep apnea. J Thorac Dis 2015;7:1311-22.

4 Cavaliere M, Russo F, Iemma M. Awake versus drug-induced sleep endoscopy: evaluation of airway obstruction in obstructive sleep apnea/hypopnoea syndrome. Laryngoscope 2013;123:2315-8.
5 Fernández-Julián E, García-Pérez MÁ, García-Callejo J, et al. Surgical planning after sleep versus awake techniques in patients with obstructive sleep apnea. Laryngoscope 2014;124:1970-4.

6 Koutsourelakis I, Safiruddin F, Ravesloot M, et al. Surgery for obstructive sleep apnea: sleep endoscopy determinants of outcome. Laryngoscope 2012;122:2587-91.

7 Montevecchi F, Cammaroto G, Meccariello G, et al. Transoral robotic surgery (TORS): a new tool for high risk tracheostomy decannulation. Acta Otorhinolaryngol Ita 2017;37:46-50.

8 Dedhia RC, Rosen CA, Soose RJ. What is the role of the larynx in adult obstructive sleep apnea? Laryngoscope 2014;124:1029-34.

9 Monnier P. Pediatric airway surgery: management of laryngotracheal stenosis in infants and children. Berlin: Springer 2010.

10 Verse T, Kroker B, Pirsing W, et al. Tonsillectomy for treatment of obstructive sleep apnea in adults with tonsillar hypertrophy. Laryngoscope 2000;110:1556-9.

11 Vicini C, Hendawy E, Campanini A, et al. Barbed reposition pharyngoplasty (BRP) for OSAHS: a feasibility, safety, efficacy and teachability pilot study. "We are on the giant's shoulders”. Eur Arch Otorhinolaryngol 2015;272:3065-70.

12 Barbieri M, Salami A, Mora F, et al. High frequency surgery in the treatment of turbinate hypertrophy: 11's years' experience. Acta Otorhinolaryngol Ita 2003;23:436-9.

13 Passali FM, Bellussi L, Mazzone S, et al. Predictive role of nasal functionality tests in the evaluation of patients before nocturnal polysomnografic recording. Acta Otorhinolaryngol Ita 2011;31:103-8.

14 Passali D, Caruso G, Arigliano LC, et al. Database application for patients with obstructive sleep apnoea syndrome. Acta Otorhinolaryngol Ita 2012;32:252-5.

15 Piazza C, Mangili S, Bon FD, et al. Preoperative clinical predictors of difficult laryngeal exposure for microlaryngoscopy: the Laryngoscore. Laryngoscope 2014;124:2561-7.

16 Rosenthal LD, Dolan DC. The Epworth Sleepiness Scale in the identification of obstructive sleep apnea. J Nerv Ment Dis 2008;196:429-31.

17 Belafsky PC, Mouadeb DA, Rees CJ, et al. Validity and reliability of the Eating Assessment Tool (EAT-10). Ann Otol Rhinol Laryngol 2008;117:919-24.

18 Robbins J, Coyle J, Rosenbek J, et al. Differentiation of normal and abnormal airway protection during swallowing using the penetration-aspiration scale. Dysphagia 1999; 14:228-32.

19 De Vito A, Carrasco Llatas M, Vanni A, et al. European position paper on drug-induced sedation endoscopy (DISE). Sleep Breath 2014;18:453-65.

20 Barbieri M, Del Piazzo A, Della Casa P, et al. La Sleep Endoscopy come criterio di valutazione pre-chirurgica nei pazienti affetti da turbe del sonno. Valsalva 2009 Vol LXXXV n 3/4. 
21 Vicini C, De Vito A, Benazzo M, et al. The nose oropharynx hypopharynx and larynx (NOHL) classification: a new system of diagnostic standardized examination for OSAHS patients. Eur Arch Otorhinolaryngol 2012;269:1297-300.

22 Sorrenti G, Piccin O. Functional expansion pharyngoplasty in the treatment of obstructive sleep apnea. Laryngoscope 2013;123:2905-8.

23 Mantovani M, Rinaldi V, Torretta S, et al. Barbed Roman blind technique for the treatment ob obstructive sleep apnea: how we do it? Eur Arch Otorhinolaryngol 2016;273:517-23.

24 Salamanca F,Constantini F, Mantovani M, et al. Barbed an- terior pharyngoplasty: an evolution of anterior palatoplasty. Acta Otorhinolaryngol Ital 2014;34:434-8.

25 Friedman M, Tanyeri H, La Rosa M, et al. Clinical predictors of obstructive sleep apnea. Laryngoscope 1999;109:1901-7.

26 Bourolias C, Hajiioannou J, Sobol E, et al. Epiglottis reshaping using CO2 laser: a minimally invasive technique and its potent applications. Head Face Med 2008;4:15.

27 Lin HC, Friedman M, Chang HW, et al. Z-palatopharyngoplasty combined with endoscopic coblator open tongue base resection for severe obstructive sleep apnea/hypopnea syndrome. Otolaryngol Head Neck Surg 2014;150:1078-85.

Received: July 10, 2017 - Accepted: September 1, 2017

Address for correspondence: Valeria Roustan, Department of Otorhinolaryngology and Head and Neck Surgery, University of Genoa, San Martino Hospital, largo Rosanna Benzi 10, 16132 Genoa, Italy. E-mail: valeria.roustan@gmail.com 